\title{
Determination of the optimal investment portfolio using CAPM in Tehran Stock Exchange industries: A VAR-Multivariate GARCH approach
}

\author{
Seyed Ahmad Hosseini ${ }^{a^{*}}$, Ahmad Moradifard ${ }^{\mathrm{a}}$ and Kobra Sabzzadeh ${ }^{\mathrm{b}}$
}

${ }^{a}$ Department of Industrial Engineering, K.N Toosi University of Technology, Tehran, Iran

${ }^{b}$ Safir Danesh Nonprofit Institute, Ilam, Iran

\begin{tabular}{l}
\hline A R T I C L E I N F O \\
\hline Article history: \\
Received 16 August 2012 \\
Received in revised format \\
14 September 2012 \\
Accepted October 202012 \\
Available online \\
23 October 2012 \\
\hline Keywords: \\
Capital asset pricing model \\
Multivariate GARCH model \\
Value at Risk \\
Portfolio selection model
\end{tabular}

\section{A B S T R A C T}

\begin{abstract}
This study determines the optimal investment portfolio in Tehran Stock Exchange (TSE) industries. For this purpose, a conditional capital asset pricing model (CAPM) with time-varying covariance, according to a Multivariate GARCH approach has been formulated. According to this conditional CAPM, the conditional variance-covariance matrix and mean of returns are calculated for some industries. By using the Mean-Value at Risk portfolio selection model, the optimum proportion is detected. Results showed that the Pharmaceutical Industry, Financial Group and Cement Industry have the most quotas in portfolio since they maintain the minimum variance and maximum return among all other industries.
\end{abstract}

C) 2013 Growing Science Ltd. All rights reserved

\section{Introduction}

The capital asset pricing model (CAPM) was originally proposed by Sharp (1964) and Lintner (1965), independently. This model is based on the assumption that individual investors will hold only meanvariance efficient portfolio. In other words, there are no other portfolios, which would offer a higher return for the same level of risk or a similar return for a lower level of risk (Morelli, 2003). CAPM has provided a straightforward and compelling theory of asset market pricing for many years (Bollerslev et al., 1988).

Engle (1982) is believed to be the first who introduced the idea of ARCH model and various studies on CAPM in conditional form have been performed (Ferson et al., 1987). They developed this model by allowing expected risk premiums and market betas to vary over time. Bollerslev et al. (1988) considered time varying covariance in their study and estimated a Multivariate GARCH model for returns to bills, bonds and stocks in US. Their results showed that the conditional covariances are quite variable over time. Bodurtha and Mark (1991) and $\mathrm{Ng}$ (1991) also modeled the variance and covariance of CAPM variables over time according to Engle's autoregressive conditional heteroskedasticity

* Corresponding author. Tel: +98911 2166544

E-mail: s_ahmadhosseini@yahoo.com (S. A. Hosseini)

(C) 2013 Growing Science Ltd. All rights reserved. doi: $10.5267 /$ j.ijiec.2012.010.002 
(ARCH) model. De Santis Gerard (1997) implemented Multivariate GARCH model to consider variance and covariance components in CAPM over time. They tested this conditional CAPM for the world's eighth largest equity markets. Morelli (2003) investigated conditional and unconditional versions of the CAPM on UK securities by using the ARCH type family of models. He compared the systematic risk factor (beta) of the security in conditional and unconditional asset pricing model and found that these values correlated, depending on the method used.

After representing Modern Portfolio Theory by Markowitz (1952), various risk measures have been developed to extend this model. Value at Risk was one of these measures introduced by Till Guldimann (1980), which shows the maximum potential loss, during a defined period, under a given probability.

In this paper, we construct an optimal portfolio for various industries in Tehran Stock Exchange (TSE). By considering conditional variance and covariance, conditional CAPM is represented. Optimum proportions in various industries are detected by using mean-VaR portfolio selection model. For this purpose, the CAPM's feature is reviewed in section 2. By representing the ARCH and M-GARCH models in section 3 and 4, conditional CAPM is represented in section 5. To consider these industries as a dynamic construction, Vector Autoregressive model has been represented in section 6. In section 7, Markowitz mean-variance model has been introduced. The Value at Risk has been represented in section 8 as the portfolio selection model risk measure and the Mean-VaR portfolio selection model is represented in section 9. To determine conditional variance, covariance and conditional mean of returns for conditional CAPM, various tests like stationary test and the ARCH-LM test, are used to detect the suitable VAR-Multivariate GARCH model in section 10. Finally, the optimum proportions are determined by using these conditional variance, covariance and mean of returns and the Mean-VaR portfolio selection model in section 11 .

\section{The Capital Asset Pricing Model}

The capital asset pricing model (CAPM), originally proposed by Sharp (1964) and Lintner (1965) independently following the suggestion of mean variance optimization in Markowitz (1952) has provided a straightforward and compelling theory of asset market pricing for many years (Bollerslev et al., 1988). This model is based on the assumption that individual investors will hold only mean variance efficient portfolios. The theory of the model tries to predict the expected return of an asset as the combination of the risk free rate and a proportion of the nondiversifiable risk (systematic or market risk), which is measured by the covariance of the asset return with the market portfolio (Bollerslev et al., 1988). According to this model, the expected return can be expressed as:

$E\left(R_{i}\right)=R_{F}+\left(E\left(R_{M}\right)-R_{F}\right) \beta_{i}$

Where $E\left(R_{i}\right)$ is the expected return of security $i, R_{M}$ is the market return, $R_{F}$ is the risk free rate of return and $\beta_{i}$ is the systematic risk measure for security $i$. Systematic risk measure $\left(\beta_{i}\right)$ can be derived as the coefficient of a linear regression between the security return and the market return:

$R_{i t}=\alpha_{0}+\beta_{i} R_{M t}+\varepsilon_{i t}$,

where

$\beta_{i}=\frac{\operatorname{Cov}\left(R_{i}, R_{M}\right)}{\operatorname{Var}\left(R_{M}\right)}$

\section{Autoregressive Conditional Heteroskedasticity Models}

In conventional econometrics models, it is assumed that residuals variance is constant over sample time period (homoscedastic), while analyzing different financial time series like GDP growth rate, exchange rate and etc. demonstrate that most of these series do not maintain constant return and they have different volatility over time. This feature is called volatility clustering which describes that these series 
have low volatility in one period and high volatility in another one. According to these explanations, the assumption of constant variance or homoscedasticity is not so reasonable.

Engle (1982) formulated this process and developed autoregressive conditional heteroskedasticity (ARCH) model, which allows conditional variance to change over time. In order to model these time series, if one assumes that the series follows a first order autoregressive process, then:

$r_{t}=a_{0}+a_{1} r_{t-1}+\varepsilon_{t}$.

The residuals are normally distributed with mean zero and variance $h_{t}$

$\varepsilon_{t} \mid I_{t} \square N\left(0, h_{t}\right)$,

where

$\operatorname{Var}\left(\varepsilon_{t} \mid I_{t-1}\right)=E\left(\varepsilon_{t}^{2} \mid I_{t-1}\right)=h_{t}=\alpha_{0}+\sum_{j=1}^{q} \alpha_{i} \varepsilon_{t-j}^{2}$,

where $q$ represents the order of the process, the conditional variance is given as a linear function of past squared errors (Morelli, 2003).

Bollerslev (1986) extended Engle's ARCH model to the generalized autoregressive conditional heteroskedasticity $(\mathrm{GARCH})$ model. The GARCH model allows the conditional variance to be dependent upon previous own lags, so that a GARCH process of order $(p, q)$ is given by:

$$
\operatorname{Var}\left(\varepsilon_{t} \mid I_{t-1}\right)=E\left(\varepsilon_{t}^{2} \mid I_{t-1}\right)=h_{t}=\alpha_{0}+\sum_{j=1}^{q} \alpha_{i} \varepsilon_{t-j}^{2}+\sum_{j=1}^{p} \beta_{j} h_{t-j}
$$

\section{Multivariate GARCH models}

Nowadays it is widely accepted that financial volatility moves between different markets and VARIOUS financial assets. Autoregressive Conditional Heteroskedasticity models are now widely implemented to describe financial time series volatility changes.

Multivariate GARCH models were developed from simple GARCH models and they were extended in last 1990's. Most application of these models is the analysis of volatility relationship between different markets. These models are similar to their univariate counterpart, except that they also consider covariances movement over time (Brooks, 2008). Let $r_{t}$ be the security return time series as follows,

$r_{t}=a_{0}+a_{1} r_{t-1}+\varepsilon_{t}$

and

$\varepsilon_{t}=H_{t}^{1 / 2} Z_{t}$

where

$E\left(z_{t}\right)=0, \operatorname{Var}\left(z_{t}\right)=I_{N}$

and $H_{t}^{1 / 2}$ is a $N \times N$ is positive definite matrix and $H_{t}$ is the conditional variance of $\varepsilon_{t}$ as follows,

$H_{t}=\operatorname{Cov}\left(\varepsilon_{t} \mid I_{t-1}\right)$

In $H_{t}$ modeling, Multivariate GARCH modeling is different (Bauwens et al., 2006) and two different Multivariate GARCH formulations have been proposed in the literature, including the VECH and BEKK models. 


\subsection{The VECH Model}

According to Bollerslev et al. (1988), a common specification of the VECH model is as follows,

$$
\operatorname{vech}\left(H_{t}\right)=C+A \operatorname{vech}\left(\varepsilon_{t-1} \varepsilon_{t-1}^{\prime}\right)+B \text { vech }\left(H_{t-1}\right) \varepsilon_{t} \mid \psi_{t-1} \square N\left(0, H_{t}\right)
$$

where $H_{t}$ is a $N \times N$ conditional variance-covariance matrix, $\varepsilon_{t}$ is an $N \times 1$ innovation vector, $\psi_{t-1}$ represents the information set at time $t-1, C$ is a $N(N+1) / 2 \times 1$ parameter vector, $A$ and $B$ are $N(N+1) / 2 \times N(N+1) / 2$ parameter matrices and $\operatorname{VECH}($.$) denotes the column-stacking$ operator applied to the upper portion of the symmetric matrix (Brooks, 2008).

\subsection{The BEKK Model}

The BEKK model (Engle \& Kroner, 1995) addresses the difficulty with VECH of ensuring that the $H_{t}$ matrix is always positive definite. It is represented by:

$$
H_{t}=w^{\prime} w+A^{\prime} H_{t-1} A+B^{\prime} \varepsilon_{t-1} \varepsilon_{t-1}^{\prime} B
$$

where $A$, and $B$ are $N \times N$ matrices of parameters and $W$ is an upper triangular matrix of parameters. The positive definiteness of the covariance matrix is ensured owing to the quadratic nature of the terms on the equation's right hand side (Brooks, 2008).

\section{Conditional Capital Asset Pricing Model}

The conditional CAPM allows the variance and covariance of security $i$ to be time varying. Conditional CAPM can be shown as:

$E\left(R_{i t} \mid I_{t-1}\right)=R_{F}+\beta_{i} \mid I_{t-1}\left(E\left(R_{M t} \mid I_{t-1}\right)-R_{F}\right)$,

where

$\beta_{i} \mid I_{t-1}=\operatorname{Cov}\left(R_{i t}, R_{M t} \mid I_{t-1}\right) / \operatorname{Var}\left(R_{M t} \mid I_{t-1}\right)$.

To define variance-covariance matrix values, various M-GARCH models can be used. In this research, the BEKK model has been used as it ensures $H_{t}$ matrix to be always positive definite.

\section{VAR}

By increasing the efficiency of markets and globalization of the financial markets and also high developments in internet communications, price volatility has moved quickly among various markets. For this reason, financial markets have been dependent to each other more than past and they must be considered as a dynamic construction. Requests transfer from different industries in stock exchange market can be a typical example of this subject. Detecting this relationship among various markets is one of the most important objects in financial modeling. For this purpose, Sims (1980) popularized vector autoregressive models (VARs) in econometrics. VARs are vector form of simple AR models where contains more than one equation. Standard form of this model is as below:

$x_{t}=A_{0}+A_{1} x_{t-1}+\varepsilon_{t}^{\prime}$,

where $x_{t}$ is the coefficient matrix, $A_{0}$ is the intercept matrix, $A_{1}$ is the polynomials matrix in terms of the lag operator and $\varepsilon_{t}^{\prime}$ is the white noise matrix. So, vector autoregressive models can be displayed as: 


$$
\left[\begin{array}{l}
x_{1 t} \\
x_{2 t} \\
\cdots \\
\cdots \\
\cdots \\
x_{n t}
\end{array}\right]=\left[\begin{array}{l}
A_{10} \\
A_{20} \\
\cdots \\
\cdots \\
\cdots \\
A_{n 0}
\end{array}\right]+\left[\begin{array}{llll}
A_{11}(L) & A_{12}(L) & \cdots & A_{1 n}(L) \\
A_{21}(L) & A_{22}(L) & \cdots & A_{2 n}(L) \\
\cdots & \cdots & \cdots & \cdots \\
\cdots & \cdots & \cdots & \cdots \\
\cdots & \cdots & \cdots & \cdots \\
A_{n 1}(L) & A_{n 2}(L) & \cdots & A_{n n}(L)
\end{array}\right]\left[\begin{array}{l}
x_{1 t-1} \\
x_{2 t-1} \\
\cdots \\
\cdots \\
\cdots \\
x_{n t-1}
\end{array}\right]+\left[\begin{array}{l}
\varepsilon_{1 t}^{\prime} \\
\varepsilon_{2 t}^{\prime} \\
\cdots \\
\cdots \\
\cdots \\
\varepsilon_{n t}^{\prime}
\end{array}\right]
$$

\section{Mean-Variance Portfolio Selection Model}

This model was first represented by Harry Markowitz in 1952 and is the most common and famous approach in portfolio selection problems with the following assumptions,

1. Risk of a portfolio is based on the variability of returns from the said portfolio.

2. An investor is risk averse.

3. An investor prefers to increase consumption.

4. The investor's utility function is concave and increasing, due to his risk aversion and consumption preference (Markowitz, 2005).

5. Analysis is based on single period model of investment (Markowitz, 2005).

6. An investor either maximizes his portfolio return for a given level of risk or maximum return for minimum risk (Markowitz, 2009).

7. An investor is rational in nature (Markowitz, 2005).

To choose the best portfolio from a number of possible portfolios, each with different return and risk, two separate decisions are to be made:

1. Determination a set of efficient portfolios.

2. Selection of best portfolio out of the efficient set

Markowitz modeled the portfolio selection problem as a quadratic programming with minimum portfolio variance in objective function subject to that the expected return of the portfolio to be greater than a specified return. There are also two important constraints in this model, where summation of assets weights in portfolio must be equal to one and each of these weights should be a real non negative number (short selling is forbidden). This model was represented as below:

$\min \quad Z=\sum_{i=1}^{n} \sum_{j=1}^{n} w_{i} w_{j} \sigma_{i j}$

subject to

$$
\begin{aligned}
& \sum_{i=1}^{n} w_{i} \bar{R}_{i} \geq d \\
& \sum_{i=1}^{n} w_{i}=1
\end{aligned}
$$

$w_{i} \geq 0$ 


\section{Value at Risk}

Standard deviation of the portfolio return distribution is one of the common risk measures. Facility of usage, calculation and comparability among different portfolios, make this measure more popular. Nowadays, with the development of asset and liabilities management systems, measuring Value at Risk is important.

The Value at Risk is one of the major risk indicators for financial portfolio or product. It was introduced by Till Guldimann in 1980 and then was extended by J.P. Morgan institute in the late 1980 's. It provides a measure of the maximal potential loss, during a defined period, under a given probability for a financial product or portfolio. The maximal potential loss of a portfolio can be measured by its return probability distribution function. This evident is illustrated in Fig 1.

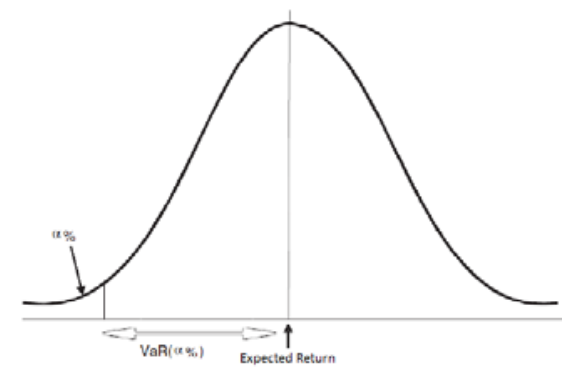

Fig.1. Value at Risk in a normal returns function

For instance, the Value at Risk under confidence level of $99 \%$ and 10 day time horizon indicates that, the maximum expected loss exceeds only for one time over per 100 samples from VaR over these 10 days. According to these explanations, Value at Risk can be calculated as follow:

$\operatorname{VaR}_{1-\alpha}=-F_{x}^{-1}(\alpha)=-\inf \left[x \mid F_{x}(x) \geq \alpha\right]$

Value at Risk's calculation methods can be divided into two types of parametric and nonparametric methods. Parametric method contains variance-covariance and some analytical methods and nonparametric method contain Monte Carlo simulation and historical simulation methods (Frank, 2004). In this research, Value at Risk approach is used as the risk measure in portfolio selection model.

\section{Mean-VaR Portfolio Selection Model}

Mean-VaR model is basically constructed according to Markowitz mean variance model as regards it has the Value at Risk as the risk measure in its objective function. This model is represented as below:

$$
\min : \operatorname{VaR}_{p}=E\left(\bar{R}_{p}\right)-z_{\alpha} \sqrt{w^{\prime} \sum_{r} w}=\sum_{i=1}^{n} w_{i} \bar{R}_{i}-z_{\alpha} \sqrt{\sum_{i=1}^{n} \sum_{j=1}^{n} \sigma_{i j} w_{i} w_{j}}
$$

subject to

$$
\begin{gathered}
\sum_{i=1}^{n} w_{i} \bar{R}_{i} \geq d \\
\sum_{i=1}^{n} w_{i}=1 \\
w_{i} \geq 0
\end{gathered}
$$

$\operatorname{VaR}_{p}$ : Portfolio's Value at Risk

$n:$ Indices number

$w_{i}$ : The proportion of industry $i$ in the portfolio 
$\bar{R}_{i}$ : Expected return of industry $i$

$\sigma_{i j}:$ Variance-covariance matrix

$d$ : Minimum level of investor expected return

\section{Numerical Analysis}

\subsection{Data}

The data is obtained from the Tehran Stock Exchange (TSE) database. The sample period begins at the first of January 2005 and finishes at the end of September 2012. The data used is monthly return on ten different TSE industries, which contain more than 90 percent of TSE's market value. These industries are: Multidisciplinary Industrial, Bank, Automobile Industry, Metal Ores, Chemical Industry, Pharmaceutical Industry, Cement Industry, Financial Group, Petroleum Refining Industry and Basic Metals Group. The returns of these industries are defined as follows:

$R_{t}=\ln \left(P_{t}\right)-\ln \left(P_{t-1}\right)$,

where $R_{t}$ is the return of month $t, \operatorname{Ln}$ is the logarithm and $P_{t}$ is the price index of the industry at the end of month $t$.

\subsection{Stationary Test}

Stationary, is the basis of time series analysis. Stationary series express that the volatility of data are constant on a specific level over time. To test the stationary, the existence of unit root was reviewed in each series. For this purpose, Augmented Dickey-Fuller test is used and the results are exhibited in Table 1.

\section{Table 1}

Stationary Test of Time Series

\begin{tabular}{lcccc}
\multicolumn{1}{c}{ Time Series } & ACD Statistic & Critical Level (5\%) & Critical Level (10\%) & Stationary \\
\hline Market Index & -5.712 & -1.944 & -1.614 & Positive \\
Bank & -9.201 & -1.944 & -1.614 & Positive \\
Multidisciplinary Industrial & -6.636 & -1.944 & -1.614 & Positive \\
Pharmaceutical Industry & -6.011 & -1.944 & -1.614 & Positive \\
Basic Metals Group & -6.131 & -1.944 & -1.614 & Positive \\
Metal Ores & -6.721 & -1.944 & -1.614 & Positive \\
Automobile Industry & -7.559 & -1.944 & -1.614 & Positive \\
Petroleum Refining Industry & -7.243 & -1.944 & -1.614 & Positive \\
Financial Group & -8.630 & -3.459 & -3.155 & Positive \\
Chemical Industry & -7.281 & -1.944 & -1.614 & Positive \\
Cement Industry & -7.336 & -3.459 & -3.155 & Positive \\
\hline
\end{tabular}

The results explicitly show that, none of the time series has unit root at the critical level of $5 \%$ and $10 \%$. This shows that all these time series have stationary.

\subsection{Autoregressive Conditional Heteroskedasticity (ARCH) Test}

In order to test the existence of ARCH effects in residuals of each time series, an ARMA model is estimated for each series and then the ARCH-LM test is used to check the Heteroskedasticity effect in series. Results are exhibited in Table 2. According to these results, most of the time series have conditional heteroskedasticity in their error terms except the Pharmaceutical Industry, Automobile Industry and Financial Group time series. In other words, these time series variance should be considered homoscedastic (constant). 
Table 2

The ARCH-LM Test

\begin{tabular}{lccc}
\hline Time Series & F Statistic & Probability & ARCH Effect \\
\hline Market Index & 6.436 & 0.0129 & Positive \\
Bank & 4.012 & 0.0479 & Positive \\
Multidisciplinary Industrial & 8.896 & 0.0037 & Positive \\
Pharmaceutical Industry & 0.071 & 0.7905 & Negative \\
Basic Metals Group & 9.425 & 0.0028 & Positive \\
Metal Ores & 7.323 & 0.0081 & Positive \\
Automobile Industry & 0.055 & 0.8157 & Negative \\
Petroleum Refining Industry & 4.179 & 0.0439 & Positive \\
Financial Group & 0.0002 & 0.9864 & Negative \\
Chemical Industry & 6.521 & 0.0167 & Positive \\
Cement Industry & 6.792 & 0.0144 & Positive \\
\hline
\end{tabular}

\subsection{VAR-Multivariate GARCH Model Estimation}

In order to forecast variance-covariance matrix for the next period (month), Diagonal BEKK model because of its benefits to other Multivariate GARCH models- is used in this research.

\subsubsection{VAR estimation}

Results of VAR estimation for four lag are exhibited in summary in Table 3.

Table 3

The VAR Estimation

\begin{tabular}{cccc}
\hline Lag & AIC Criteria & SC Criteria & HQ Criteria \\
\hline 0 & -27.406 & -24.351 & -26.175 \\
1 & $-27.864^{*}$ & $-27.587^{*}$ & $-27.752^{*}$ \\
2 & -26.933 & -21.101 & -24.581 \\
3 & -26.352 & -17.741 & -22.880 \\
4 & -25.979 & -14.592 & -21.387 \\
\hline
\end{tabular}

The results show the first lag as the optimum lag.

\subsubsection{Diagonal BEKK estimation}

In this section, optimum ARCH and GARCH lags in Diagonal BEKK model is estimated on VAR for return time series. Results of this estimation are exhibited in Table 4, where $q$ represents ARCH's lag and $p$ represents GARCH's lag.

Table 4

Optimum Lag in Multivariate GARCH Model

\begin{tabular}{ccccc}
\hline ARCH's Lag $(q)$ & GARCH's Lag $(p)$ & AIC Criteria & SC Criteria & HQ Criteria \\
\hline 0 & 1 & -26.209 & -21.471 & -24.296 \\
1 & 1 & $-26.276^{*}$ & $-21.811^{*}$ & $-24.473^{*}$ \\
1 & 2 & -26.003 & -20.992 & -23.979 \\
2 & 1 & -25.288 & -20.277 & -23.265 \\
2 & 2 & -25.558 & -20.275 & -23.425 \\
\hline
\end{tabular}

All the AIC, SC and HQ criteria, specified the GARCH $(1,1)-B E K K$ model as the optimum model.

\subsection{Conditional Variance-Covariance Matrix}

By estimating optimal lags in Multivariate GARCH model, conditional variance-covariance matrix is forecasted for the next period according to $\operatorname{VAR}(1)-G A R C H(1,1)-B E K K$ model. This matrix is displayed in Table 5. 
Table 5

Variance-Covariance Matrix

\begin{tabular}{cccccccccccc}
\hline & MaI & B & MuI & PI & BMG & MO & AI & PRI & FG & ChI & CeI \\
\hline MaI & 1.39 & 0.85 & 1.53 & 0.79 & 1.97 & 2.07 & 1.21 & 1.5 & 1.01 & 1.94 & 0.67 \\
B & 0.85 & 9.63 & 1.49 & 0.61 & 0.91 & -0.14 & 1.56 & 0.5 & 1.13 & 1.17 & 2.06 \\
MuI & 1.53 & 1.49 & 4.45 & 0.91 & 2.29 & 2.87 & 1.69 & 1.21 & 1.62 & 1.65 & 0.86 \\
PI & 0.79 & 0.61 & 0.91 & 1.57 & 1.12 & 1.67 & 1.44 & 1.06 & 0.65 & 0.92 & 0.28 \\
BMG & 1.97 & 0.91 & 2.29 & 1.12 & 4.62 & 4.73 & 0.64 & 1.92 & 0.85 & 2.27 & 0.53 \\
MO & 2.07 & -0.14 & 2.87 & 1.67 & 4.73 & 9.42 & 1.79 & 2.61 & 1.55 & 3.49 & 0.26 \\
AI & 1.21 & 1.56 & 1.69 & 1.44 & 0.64 & 1.79 & 4.75 & 0.9 & 1.84 & 0.98 & 0.89 \\
PRI & 1.5 & 0.5 & 1.21 & 1.06 & 1.92 & 2.61 & 0.9 & 5.26 & 0.98 & 2.96 & 1.23 \\
FG & 1.01 & 1.13 & 1.62 & 0.65 & 0.85 & 1.55 & 1.84 & 0.98 & 1.83 & 1.22 & 0.61 \\
ChI & 1.94 & 1.17 & 1.65 & 0.92 & 2.27 & 3.49 & 0.98 & 2.96 & 1.22 & 4.44 & 1.49 \\
CeI & 0.67 & 2.06 & 0.86 & 0.28 & 0.53 & 0.26 & 0.89 & 1.23 & 0.61 & 1.49 & 2.55 \\
\hline *All numbers in the
\end{tabular}

\subsection{Conditional Mean of Returns}

As we know, mean, variance and covariance are the most important factors in portfolio selection models. In this section, conditional mean of returns time series are estimated by using Eq. (1), Eq. (3) and the conditional values of Market Index variance and covariances in Table 5. Risk free rate of return is obtained from the common annual investment rate in banking system and is equal to 0.17 , which can be considered 0.013 per month. Table 6 shows the conditional mean of return calculated by the conditional CAPM model.

\section{Table 6}

Conditional Mean of Return

\begin{tabular}{lcc}
\hline Time Series & Systematic Risk (Beta $i)$ & Conditional Mean of Return \\
\hline Bank & 0.61 & 9.33 \\
Multidisciplinary Industrial & 1.10 & 6.39 \\
Pharmaceutical Industry & 0.57 & 9.59 \\
Basic Metals Group & 1.42 & 4.49 \\
Metal Ores & 1.49 & 4.06 \\
Automobile Industry & 0.87 & 7.77 \\
Petroleum Refining Industry & 1.08 & 6.52 \\
Financial Group & 0.73 & 8.64 \\
Chemical Industry & 1.39 & 4.63 \\
Cement Industry & 0.48 & 10.11 \\
\hline *All numbers in conditional mean of return column have $10^{-3}$ coefficient & \\
\hline
\end{tabular}

\section{Determination of Optimal Portfolio}

According to Eq. (20) and variance, covariance and mean values in Table 5 and 6, optimal investment proportion in Tehran Stock Exchange different industries has been detected.

\section{Table 7}

Conditional Mean of Return

\begin{tabular}{lcccc}
\hline Industries & \multicolumn{3}{c}{ Optimal Proportion } \\
\hline Bank & 0 & 0 & 0 & 0 \\
Multidisciplinary Industrial & 0 & 0 & 0 & 0 \\
Pharmaceutical Industry & 0.46 & 0.46 & 0.46 & 0.21 \\
Basic Metals Group & 0 & 0 & 0 & 0 \\
Metal Ores & 0 & 0 & 0 & 0 \\
Automobile Industry & 0 & 0 & 0 & 0 \\
Petroleum Refining Industry & 0 & 0 & 0 & 0 \\
Financial Group & 0.27 & 0.27 & 0.27 & 0 \\
Chemical Industry & 0 & 0 & 0.27 & 0.79 \\
Cement Industry & 0.27 & 0.27 & 0.008 & 0.01 \\
Expected Return $(d)$ & 0.004 & 0.006 & 0.00 & \\
\hline
\end{tabular}


The results show that, those industries with minimum variance and maximum return have the most quotas in portfolio.

\section{Conclusion}

The capital asset pricing model (CAPM) is based on the assumption that individual investors hold only the efficient portfolio. In other words, there are no other portfolios, which would offer a higher return for the same level of risk or a similar return for a lower level of risk.

By using Engle and Kroner's Multivariate GARCH model (BEKK), the conditional capital asset pricing model formulation has been represented. According to this model, the conditional variancecovariance matrix and the conditional CAPM components of TSE's different industries return time series were calculated.

Optimal investment proportion has been detected by using the Mean-VaR portfolio selection model. The results of our survey have demonstrated that the Pharmaceutical Industry, Financial Group and Cement Industry can be considered as the best options for investment planning and the reason is primarily because of their minimum risk and maximum return among these industries.

\section{References}

Bauwens, L., Laurent, S., \& Rombouts, V. K. (2006). Multivariate GARCH Models: A Survay . Applied Econometrics,21(1), 79-109.

Bodurtha, J. N., \& Mark, N. C. (1991). Testing the CAPM with Time-Varying Risk and Returns. The Journal of Finance,46(4), 1485-1505.

Bollerslev, T. (1986). Generalised Autoregressive Conditional Heteroskedasticity . Journal of Econometrics,31(3), 307-327.

Bollerslev, T., Engle, R. F., \& Wooldridge, J. M. (1988). A Capital Asset Pricing Model with TimeVarying Covariances. The Journal of Political Economy, 96(1), 116-131.

Brooks, C. (2008). Introductory Econometrics for Finance. New York: Cambridge University Press.

De Santis, G., \& Gerard, B. (1997). International Asset Pricing and Portfolio Diversification with Time-Varying Risk. Journal of Finance,52(5), 1881-1912.

Engle, R. F. (1982). Autoregressive Conditional Heteroskedasticity with Estimates of the Varince of United Kingdom Inflation. Econometrica,50(4), 987-1007.

Engle, R. F., \& Kroner, K. F. (1995). Multivariate Simultaneous Generalised GARCH . Econometrics Theory,11(1), 122-150.

Ferson, W. E., Kandel, S., \& Stambaugh, R. F. (1987). Tests of Asset pricing with Time Vaying Expecte Risk Premuims and Market Betas. The Journal of Finance,42(2), 201-220.

Frank, J. T. (2004). Investment Manager Analyses . John Wiley and Sons.

Lintner, J. (1965). The Valuation of Risk Assets and the Selection of Risky Investments in Stocks Portfolios and Capital Budgets. Review of Economics and Statistics,47(1), 13-37.

Markowitz, H. M. (1952). Portfolio Selection. Journal of Finance,7(1), 77-91.

Markowitz, H. M. (2005). Market Efficiency: A Theoretical Distinction and So What? Finacial Analysts Journal,61(5), 17-30.

Markowitz, H. M. (2009). Harry Markowits: Selected Works. New Jersey: World Scientific.

Morelli, D. (2003). Capital Asset Pricing Model on UK Securities Using ARCH. Applied Financial Economics,13(3), 211-223.

$\mathrm{Ng}$, L. (1991). Tests of the CAPM with Time-Varying Covariances. A Multivariate GARCH Approach. Journal of Finance,46(4), 1507-1521.

Sharp, W. F. (196). Capital Asset Prices: A Theory of Mrket Equilibrium under Conditions of Risk . Journal of Finance, 19(3), 425-442. 